\title{
Nanofiber Tabakalı Hava Filtrelerinin Partikül Yakalama Performanslarının İncelenmesi
}

\author{
Kevser DÍNCER ${ }^{1}$, Gürol ÖNAL ${ }^{* 1}$, Mehmet SELBES ${ }^{1}$, Ahmet AKDEMIR ${ }^{2}$ \\ ${ }^{1}$ Selçuk Üniversitesi, Mühendislik Fakültesi Makina Mühendisliği Bölümü, Selçuklu, Konya \\ ${ }^{2}$ Necmettin Erbakan Üniversitesi, Havacılık ve Uzay Bilimleri Fakültesi, Meram, Konya
}

(Alınış / Received: 28.03.2017, Kabul / Accepted: 09.03.2018, Online Yayınlanma / Published Online: 06.05.2018)

Anahtar Kelimeler

Nanofiltre,

Nanopartikül,

Hava filtre performans testleri
Özet: Bu çalışmada, 25-85 g/m² gramaj arasındaki mikrofiber hava filtrelerinin üzerine nanofiber kaplanarak çok küçük partikülleri yakalama performansları incelenmiştir. Filtrelerin performans tayini için basınç kaybı ve partikül yakalama testleri yapılmıştır. Basınç kaybı deneylerinde filtrelere 0.3, 0.8, $1.3 \mathrm{~m} / \mathrm{s}$ hızlarında hava, partikül yakalama testleri için ise $0.3 \mathrm{~m} / \mathrm{s}$ hızında ortalama $100 \mathrm{~nm}$ çapında formda toksik olmayan $\mathrm{CaCO}_{3}$ nanopartiküllü hava kullanılmıştır. Küçük fiber çapına sahip, kesit alanı büyük, rijit ve mukavim spunbond mikrofiber filtrelerin nanofiber tabaka kaplamaya elverişli olduğu ve optimum filtreleme sağladığı belirlenmiştir. Küçük çaplı nanofiberlerin ince tabaka, büyük çaplı nanofiberlerin kalın tabakalı kaplanması filtreleme performansını arttırmaktadır. Nanofiber tabaka kaplama ağırlı̆ı̆ın artmasıyla performansın yükseldiği ve kritik bir değerden sonra filtrenin tıkanarak ömrünü tamamladığı tespit edilmiştir.

\section{Particle Infiltration Performance Investigation of Air Filters with Nanofiber Layer}

\section{Keywords}

Nanofilter,

Nanoparticule,

Performance tests of air filter

\begin{abstract}
In this study, catchingsmallparticlesperformance of nanofibercoating on microfiber air filters between $25-85 \mathrm{~g} / \mathrm{m}^{2}$ were examined. Pressure drop and particle capture tests were conducted for the determination of filter performance. For pressure loss air with the velocity of $0.3,0.8,1.3 \mathrm{~m} / \mathrm{s}$ and for particle capture tests air with $100 \mathrm{~nm}$ average diameternon-toxic $\mathrm{CaCO}_{3}$ nanoparticulate at $0.3 \mathrm{~m} / \mathrm{s}$ of were used. Microfiber filters with a small fiber diameter, largecross-sectional area, rigid and resistant spunbond were found to be suitable for coating nanofiber layer and ensure sand optimum filtering. Thin coating of small scale nanofibres the filtering performance where asthick-layer coating is found sutable for big scale nanofibers. With the increase of the nanofiber layer coating weight the performance increases and after a critical value the filter comes the end of the lifetime beacuse of blokage.
\end{abstract}

\section{Giriș}

Günümüzde hızlı sanayileșme ve nüfus artışı ile havadaki kirleticiler farklılaşmakta ve konsantrasyonu artmaktadır. Ayrıca, insanlar eskiye göre daha çok kapalı ortamlarda kalmaktadır. Bu nedenle hava filtrasyonunun önemini giderek artmaktadır. Açık havada, işte, evde soluduğumuz havanın içindeki partiküllerin büyük bir kısmı 1 $\mu$ m'dan küçüktür. Karbondioksit, nem, koku molekülleri ile, sigara dumanı, bakteri ve virüsler gibi istenmeyen veya insan sağlığına zararlı küçük partiküllerin soluduğumuz havadan uzaklaștırılması gerekir. Hava filtresi seçiminde önemli olan hangi boyuttaki partiküllerin tutulacağıdır. Örneğin, duvar tipi bir klima cihazında büyük partiküllerin filtrelenmesi, çatı tipi bir klima cihazında nispeten küçük partiküllerin yakalanması, bir ameliyathanede ise çok küçük partiküllerin tutulması gerekir. Hava filtrelerinin sınıflandırılmasıyla ilgili, ABD tarafından hazırlanan, daha çok tavsiye niteliği taşıyan standart ile CEN (European Committee for Standardization Avrupa Standartlar Komitesi) standartlar kullanılmaktadır.

Hava filtreleri yakaladıkları partikül büyüklügüne göre kaba, ince ve hassas olmak üzere üç kategoriye ayrılmaktadır. Kaba ve ince partiküllerin yakalanmasında kullanılan filtreler EN 779 standardında (Genel Havalandırma İçin Partikül Hava Filtreleri) 
tanımlanmıştır. EN 779 standardında kaba ve ince filtreler yakalanan partikül ağırlığına ve partikül tutma verimine göre sinıflandırılmıștır. Kaba, orta, ince mikrofiber filtreler genellikle 2-40 $\mu \mathrm{m}$ aralığında mikrofiberden ergitme üfleme, spunbond ve islak yatırma yöntemleri ile üretilir ve büyük taneciklerin filtrelenmesinde kullanılır. Kaba ve ince filtreler genellikle klimalar, otomobil kabin ve motor filtreleri gibi hassas olmayan yerlerde kullanılmaktadır. Ayrıca çok küçük partikül, toz ve organizma varlığının önemli olduğu yerlerde kullanılan hassas filtrelerden hemen önce kullanılmaktadır. Hassas filtreler için EN 1822 (yüksek etkinlikli hava filtreleri) standardı kullanılmaktadır. Hassas filtreler, ıslak yatırma veya elektro-eğirme metodu ile üretilen genellikle 40$1000 \mathrm{~nm}$ arasındaki nanofiberlerden meydana gelir ve çok küçük partiküllerin yakalanmasında kullanılır. Hassas filtreler geçirdikleri partikül miktarına göre sinıflandırılmış olup ameliyathaneler, mikroçip üretim tesisleri, nükleer fabrikalar, elektrikli süpürgeler gibi hassas yerlerde ve proseslerde kullanılmaktadır. İnsanların konfor beklentilerinin yükselmesi ve hassas yerlerin, süreçlerin artması yüksek etkin hava filtrelerinin önemini arttırmaktadır.

Fiber, filtrenin temel yapı elemanı olduğu için filtreleme özelliklerini en çok etkileyen faktördür. Fiber çapı azaldıkça; birim alandaki fiber miktarı artar, dolayısıyla gözenek sayısı azalır, partikülün filtre içinde alacağı yol karmaşık hale gelir. Filtrenin yüzey alanının artmasıyla, gözenek boyutu küçülür ve partikülün yakalanma ihtimali artar [1, 2]. Fiber yüzey alanı filtrasyon performansı üzerinde doğrudan bir etkiye sahiptir. Çünkü birim hacimdeki fiber yüzey alanı artışı, fiber sayısının artmasına ve partiküllerin fiber ile çarpışma ihtimallerinin artması anlamına gelir [2]. Gözeneklilik, birim hacim filtredeki boş hacim miktarı olarak tanımlanır ve birimsizdir [3].

Hava filtrelerinde genellikle tekstil esaslı filtreler kullanılır. Tekstil esaslı filtreler dokuma filtreler ve keçeler olmak üzere iki kategoride incelenebilir. Dokuma uzun ipliklerin dokunması ile elde edilir. Gramajları 20-500 g/m ${ }^{2}$ arasında değişir, mukavemetleri yüksektir. Dokuma filtreler düzenli gözenek boyutuna sahiptir. Dokuma filtrelerin kalınlığının küçük, gözenek boyutunun büyük olmasından dolayı partiküller yüzey filtrasyonu mekanizmasıyla yakalanır. Yüzey filtrasyonunda gözenek boyutundan daha büyük partiküller yüzeyde tutulur, küçük partiküller filtrede tutulmadan geçer. Yüzey filtrasyonu nedeniyle dokuma filtre gözenekleri kısa sürede tıkanır. Dokuma filtrelerin gerek kısa sürede tıkanması gerekse keçelerden pahalı olması nedeniyle hava filtrasyonunda tek başına kullanılmaz. Dokuma filtreler, keçelerle birlikte kompozit filtre temininde veya ince filtreleri takviye etmek amacıyla kullanılır [4].
Hava filtrasyonunda kullanılan keçeler ergitme üfleme, spunbond, islak yatırma ve elektro-eğirme yöntemi ile üretilir [5]. Bu metotlardan en büyük fiber spunbond yöntemi ile en küçük fiber ise elektroeğirme yöntemiyle elde edilir. Ayrıca elektro-eğirme haricindeki tüm üretim yöntemlerinde $1 \mu \mathrm{m}$ fiber çapının altına inilmesi pek mümkün değildir [5]. Hava filtrasyon mekanizmaları, genel olarak yüzey filtrasyonu, derinlik filtrasyonu ve kek filtrasyonu olmak üzere üç temel kategoride incelenir [6].

Yüzey filtrasyonunda partiküller ince bir tabaka halinde filtrenin yüzeyinde yakalanır. Yüzey filtrasyonu, partiküller ile filtre gözenekleri aynı boyutta veya partiküllerin daha büyük olması durumunda gerçekleşir. Filtreleme çok küçük bir hacimde olduğundan filtre çok kısa bir süre sonra tıkanır ve ömrünü tamamlar. $\mathrm{Bu}$ tip filtrasyon dokuma filtreler gibi homojen gözenek boyutuna sahip filtrelerde oluşur [6]. Keçeler, derinlik filtrelerine örnektir. Yüzey filtrelerine göre daha düșük verimliliğe sahip olmalarına rağmen, ucuz olmaları, ön ve esas filtre olarak kullanılabilmeleri, yüksek akışkan hızına izin vermeleri ve filtre aparatına kolay yerleştirilmeleri bakımından avantajlıdır [1].

Hem yüzey hem de derinlik filtrelerinde, partiküllerin filtre gözeneklerini tıkamasına rağmen filtrasyon devam ettiğinde; partiküller tabakalar halinde filtre kekini oluşturur. Filtre keki oluşumunun iki önemli etkisi vardır. Birincisi; kek akışa karşı direnci arttırır ve kek kalınlaştıkça akış hızı düşer. Filtrenin temizlenme zorunluluğu ortaya çıkar. İkincisi, asılı partiküllerin, filtreden önce filtre kekini olușturan partiküllerin arasındaki küçük boşluklardan geçmek zorunda olmasıdır. Bu boşluklar genellikle filtrenin kendisinden daha küçük boyutta olduğu için, filtrenin kendisinden daha etkili bir filtreleme oluștururlar. $\mathrm{Bu}$ tip filtrasyon da kek filtrasyonu olarak bilinir [1]. Elektrostatik filtrelerde, fiberlerin statik elektrikle yüklendiğinde küçük ve orta büyüklükteki partiküller yakalanır [2].

Hassas filtreler yirminci yüzyılın ortalarından yüzyılın sonuna kadar cam mikrofiberlerden elde edilmekteydi. Yirmi birinci yüzyılın bașında nano teknolojinin hızla gelişmeye başlamasıyla mikro fiberlerin yerini daha küçük fiberler almıștır. Nanofiberlerin boyutlarının küçük olması, daha etkin bir filtreme yapmasını beraberinde getirmektedir. Nanofiber üretiminde hızlı, tekrarlanabilir ve kütlesel üretime uygun olduğundan genellikle elektro-eğirme yöntemi kullanılmaktadır. Elektro-eğirme yöntemi, nispeten daha az enerjiyle, daha az maddeyle ve çok farklı polimerle nanofiber üretimine izin vermektedir. Çok çeşitli polimerlerden üretilmesi fiberlere dolayısıyla filtreye istenilen özelliklerin verilmesine imkân sağlar. Örneğin iletken nanofiber elde edilen polimerlerin kullanılmasıyla filtreye düşük bir akım verilerek havadaki pozitif partiküller kolayca yakalanabilmektedir [8]. 


\section{Deneysel Çalışma}

\subsection{Hava filtrelerinin performans testlerinde kullanılan malzemeler}

Nanofiber tabaka esnek ve ince olduğundan, rijit, yarı geçirgen ve ucuz olan mikrofiber filtreler üzerine kaplanmıștır. $\mathrm{Bu}$ mikrofiber filtreler altlık olarak adlandırılmıș olup, özellikleri Tablo 1'de sunulmuştur. Burada filtre sınıfı, filtrenin partikül yakalama hassasiyeti, $\emptyset_{\text {ort }}$ ortalama fiber çapıdır.

Tablo 1: Altlık olarak kullanılan filtrelerin özellikleri

\begin{tabular}{lllll}
\hline $\begin{array}{l}\text { Numune } \\
\text { No }\end{array}$ & Filtre ismi & $\begin{array}{l}\text { Ağırlı } \\
\left(\mathrm{g} / \mathrm{m}^{2}\right)\end{array}$ & $\begin{array}{l}\text { Filtre } \\
\text { sinıfi }\end{array}$ & $\begin{array}{l}\emptyset_{\text {ort }} \\
(\mu \mathrm{m})\end{array}$ \\
\hline $1,2,3,4$ & PET Spunbond & 85 & G4 & 20 \\
5 & $\begin{array}{l}\text { PP } \\
\text { Monofilament }\end{array}$ & 25 & G2 & 60
\end{tabular}

PET spunbond altlık üzerine kaplanan nanofiber tabakaların özellikleri Tablo 2'de gösterilmiştir. Buradaki ilk dört numune PET spunbond mikrofiber üzerine, beșinci numune ise monofilament dokuma mikrofiber üzerine kaplanmıștır. Tablo 2'de, Qmin en küçük nanofiber çapını, Qort ortalama nanofiber çapını, Qmax en büyük nanofiber çapını, standart sapma nanofiberlerin merkezi yayılma ölçüsünü ifade etmektedir. Tablo 2'deki standart sapma, söz konusu nanofiber tabakasındaki ortalama nanofiber çapının merkezi yayılma ölçüsünü ifade etmektedir. Yani, standart sapma ne kadar küçük ise nanofiber çapları ortalama nanofiber çapına o kadar yakındır. Örneğin birinci numunedeki elli adet nanofiber boyutu (çapı) ile ortalama fiber çapı arasındaki fark büyüktür. Standart sapma SEM görüntüleri kullanılarak, her bir numunede elli farklı fiber çapından yola çıkarak,

$$
\sqrt{\frac{\left(P_{1}-0\right)^{2}+\left(P_{2}-0\right)^{2}+\left(\left(P_{3}-0\right)^{2}+\ldots+(P n-0)^{2}\right.}{n-1}}
$$

ifadesinden hesaplanmıştır. Burada $\mathrm{P}_{1}$ birinci nanofiber boyutu, $\mathrm{P}_{2}$ ikinci nanofiber şeklindedir. $\mathrm{O}$, elli adet nanofiber çapının aritmetik ortalamasıdır. $n$, numune sayısıdır.

Nanofiber tabakalı filtrelerin haricinde numune olarak ve ön filtreleme amaciyla Tablo 3'de sunulan filtreler kullanılmıştır.

$\mathrm{Bu}$ filtrelerin haricinde filtre ağırlıkları ölçümünde, $1 / 10000 \mathrm{~g}$ hassasiyetinde terazi kullanılmıștır. Filtrelerin partikül yakalama testlerinde, zehirli olmaması, kolay tedarik edilmesi, ucuz olması nedeniyle 80-120 nm çapında, küresel formda $\mathrm{CaCO} 3$ nanopartikül tercih edilmiștir (Şekil 1).

Tablo 3'deki filtreler (mikro fiber filtreler ile geleneksel yöntemlerle imal edilen nanofiber filtre)'in kullanılmasındaki maksat, söz konusu filtrelerin performanslarını nanofiber tabakalı numunelerin performansı ile karşılaştırmaktır.

Tablo 2: PET Spunbond altllk üzerine kaplanan nanofiberlerin boyutları

\begin{tabular}{clccccc}
\hline $\begin{array}{c}\text { Num. } \\
\text { No }\end{array}$ & Filtre ismi & Ağırlı̆̆ $\left(\mathrm{g} / \mathrm{m}^{2}\right)$ & $\emptyset_{\min }(\mathrm{nm})$ & $\emptyset_{\text {ort }}(\mathrm{nm})$ & $\emptyset_{\max }(\mathrm{nm})$ & Stand. Sapma \\
\hline 1 & Nanofiber tabaka & 2 & 67 & 200 & 470 & 92 \\
2 & Nanofiber tabaka & 2.5 & 83 & 193 & 321 & 56 \\
3 & Nanofiber tabaka & 3 & 40 & 98 & 778 & 36 \\
4 & Nanofiber tabaka & 3.2 & 42 & 77 & 169 & 25 \\
& Nanofiber tabaka * & 4 & 73 & & & 38 \\
\hline
\end{tabular}

Tablo 3: Numune ve ön filtreleme amacıyla kullanılan mikrofiber/nanofiber filtrelerin özellikleri

\begin{tabular}{|c|c|c|c|c|c|}
\hline Num. no & Filtre ismi & Kullanma amacı & Ağırlık $\left(\mathrm{g} / \mathrm{m}^{2}\right)$ & Filtre sinıfi & $\emptyset_{\text {ort }}(\mu \mathrm{m})$ \\
\hline 6 & H 13 HEPA Nanofiltre & Numune & 85 & H13 & 0.9 \\
\hline 7 & PP Ergitme-üfleme & Numune & 110 & F7 & 8 \\
\hline 8 & PET Spunbond & Numune & 85 & G4 & 20 \\
\hline \multirow[t]{2}{*}{9} & PP Monofilament & Numune & 25 & G2 & 60 \\
\hline & PET Kaba (Elyaf) & Ön filtreleme & 125 & G2 & 50 \\
\hline
\end{tabular}


Tablo 3'deki 8. ve 9. mikrofiber filtreler ile bu filtreleri altlık olarak kullanan nanofiber tabakalı filtreler karşılaştırıldığında nanofiber tabaka ağırlı̆̆ının artması ile basınç kaybı çok hızlı bir şekilde yükselmektedir.

Fitre testlerinde, kompresörden gelen basınçlı havanın içinde bulunan su, yağ ve partikülleri tutan, sabit basınç sağlayan, 0-10 bar ve 0-500 L/dak. aralığında çalışan hava regülatörü ve filtre kullanılmıştır. Ayrıca, kanal içindeki havanın hızı hava sıcaklığı ve bağll nemi ölçmek için anemometre kullanılmıștır. Anemometre özellikleri Tablo 4'de sunulmuştur.

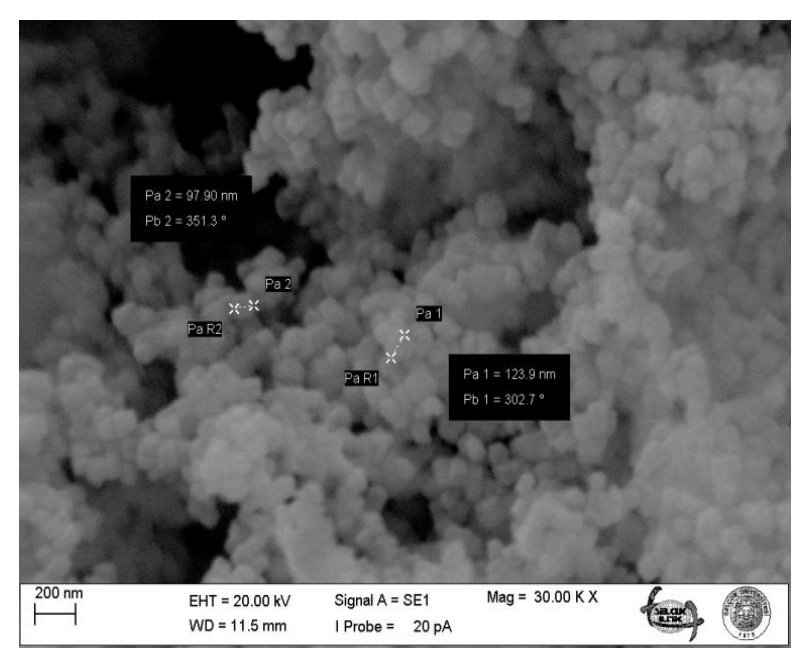

Şekil 1: $\mathrm{CaCO}_{3}$ nanopartiküllerin SEM görüntüsü

Tablo 4: Anemometre özellikleri

\begin{tabular}{lccc}
\hline \multicolumn{1}{c}{ Özellik } & Sıcaklık & Nem & Hız \\
Sensör & NTC Termistör & $\begin{array}{c}\text { Elektronik } \\
\text { direnç }\end{array}$ & Pervane \\
tipi & & & \\
Ölçme & $-5{ }^{\circ} \mathrm{C}$ ile $+65^{\circ} \mathrm{C}$ & $\% 10 \mathrm{Rh}$ ile & 0.1 ile 15 \\
aralığl & & $\% 95 \mathrm{Rh}$ & $\mathrm{m} / \mathrm{s}$ \\
Doğruluk & $\pm 1{ }^{\circ} \mathrm{C}$ & $\pm 3 \%$ & $\pm 3 \%$ \\
& & & \\
\hline
\end{tabular}

\subsection{Nanofiber ve mikrofiber hava filtrelerinin performans testleri}

Hava filtrelerinin performanslarını karşılaştırmak amacıyla iki farklı test yapılmıştır. Bunlar, basınç kaybı ve partikül tutma etkinliği testleridir. Basınç kaybı testlerinde filtreye temiz hava gönderilerek oluşan basınç kayıpları ölçülmüştür. Partikül tutma etkinliği testlerinde ise, nanopartiküllü hava filtreye gönderilmiş ve oluşan basınç kaybı ile yakalanan partikül miktarı tespit edilmiştir.

Literatürdeki çalışmalara benzer olarak basınç farkı deneyleri $0.3,0.8$ ve $1.3 \mathrm{~m} / \mathrm{s}$ hava hızlarında yapılmış ve filtrelerde meydana gelen basınç kayıpları tespit edilmiştir. Partikül yakalama deneyleri ise $0.3 \mathrm{~m} / \mathrm{s}$ hava hızında yapılmış, her beș dakikada bir yakalanan partikül miktarı ve basınç kayıpları ölçülmüştür. Nanofiber filtre performans deney parametreleri Tablo 5'de sunulmuştur.

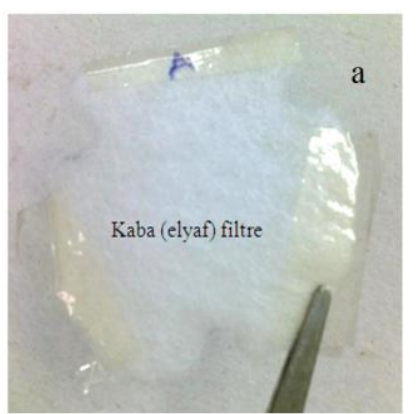

(a)

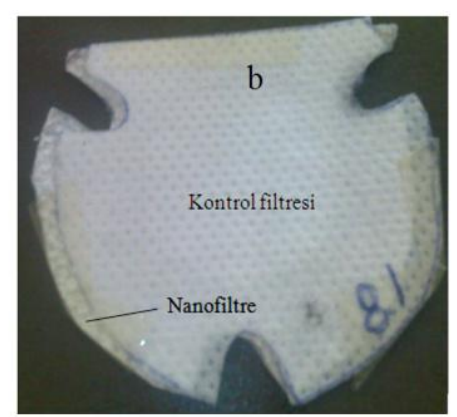

(b)

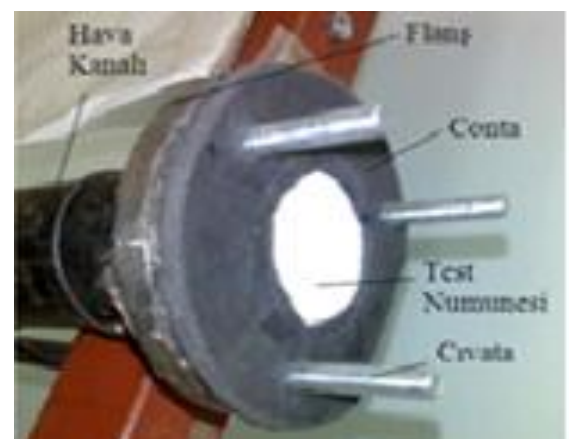

(c)

Şekil 2: Filtre performans deneylerinde kullanılan filtreler (a) kaba (elyaf) filtre, (b) kontrol filtresi ve nanofiltre (nanofiber tabaka ve altlık), (c) basınç deney cihazına yerleştirilen test numunesi

Tablo 5: Performans testleri özellikleri
Alın hızı (m/s)

Ortalama partikül boyutu

Partikül şekli

Test filtresi boyutu (mm)

Test süresi (dak.)

\section{Parametreler}

Basınç
kaybı
deneyi

$0.3,0.8,1.3$

-
$\varnothing 42$
5

\section{Partikül tutma deneyi}

0.3
100
Küresel
$\varnothing 42$
25

Deney düzeneğinde sızdırmazlık çok önemlidir. Çünkü deneylerde basınç ölçümünün çok hassas bir şekilde yapılması gerekmektedir. Bu nedenle, her iki deney düzeneği kurulduktan sonra, tüm boru ve parçaların birleşme yerlerinin sızdırmazlığının kontrol edilmesini sağlayan köpük testi uygulanmıștır. Köpük testi için su ve sıvı sabun alınarak bir pet bardak içinde iyice karıştırılmış ve köpük oluşturulmuştur. Deney düzeneğine hava verilerek, hava kanalları üzerine köpük uygulamıştır. Şayet köpükte bir şişme varsa vana kapatılarak sızdıran yer yapıştırılmıştır. Birkaç dakika sonra aynı işlem tekrarlanarak tüm düzeneğin sızdırmazlığı sağlanmıştır. Diğer yandan flanşların sızdırmazlığı için havalandırma kanallarında kullanılan NFAF ismi verilen poliüretan köpük contadan yararlanılmıştır. Flanşlar arası sızdırmazlığı sağlamak için flanşlara uygun contalar kesilerek yapıştırılmıştır.

Filtre numuneleri ve elyaf filtreler flanşa bağlanacak şekilde bir şablon hazırlanarak kesilmiştir. Numuneler kesilirken homojenliğin sağlanması 
amacıyla, filtre kenarlarından en az $5 \mathrm{~cm}$ uzakta olmasına dikkat edilmiştir. Filtrelerin kolayca merkezlenmesi ve yırtılmaması için cıvatalara denk gelen köșeleri boşaltılmıștır (Șekil 2b). Ayrıca, filtre numunelerinin flanş dışına taşmaması sağlanmıştır (Şekil 2c). Elyaf filtrelerin kenarları izole bantla yapıştırılarak rijit hale getirilerek elyaf kaybı azaltılmıştır (Şekil 2a).

\subsection{Basınç kaybı deneyleri}

Filtrelerin yakaladığı partikül miktarı kadar, filtrasyon esnasındaki basınç kaybı da önemlidir. Çünkü filtre ömrü tayininde, filtrasyon sonunda kabul edilebilir basınç kaybı kullanılır. Örneğin G sınıfı filtrelerde basınç farkı $250 \mathrm{~Pa}, \mathrm{M}$ ve F sınıfı filtrelerde $450 \mathrm{~Pa}$, HEPA filtrelerde $600 \mathrm{~Pa}$ basınç kaybına ulaşıldığında filtrenin ömrünü doldurduğu kabul edilir. Bununla beraber basınç kaybı deneyi, test numunelerinin geçirgenliğini ve farklı hava hızlarında test numunelerindeki basınç kaybını tespit etmek amacıyla yapılmıştır.

$\mathrm{Bu}$ çalışmada kullanılan basınç kaybı deney seti iki kısımdan oluşmaktadır (Bkz. Şekil 3). Bunlar ön filtreleme ve regülatör sistemi, orifis ve test filtresi bölümüdür. Ön filtreleme ve regülatör sistemi, kaba filtre, regülatör ve H13 sinıfı HEPA filtre bölümlerinden oluşmaktadır. $\mathrm{Bu}$ bölümdeki kaba filtre büyük partiküllerin, regülatör sıvı partiküllerin (yağ ve su gibi), H13 sınıfı HEPA filtre ise küçük partiküllerin filtrelenmesi amacı ile kullanılmıştır. Ayrıca, sabit hava debisi elde etmek için regülatörden yararlanılmıștır. Orifis bölümü hava kanalındaki hızı ölçmek için tasarlanmıştır.

Anemometreden ölçülen hava hızı $0.3,0.8$ ve $1.3 \mathrm{~m} / \mathrm{s}$ olduğunda orifis manometresindeki basınç farkı sirayla 15, 96 ve 247 mmSS olduğu daha önce hesaplanmıştır.

Tüm filtre numuneleri orifisten sonra monte edilmiştir. Test filtresi manometresinde yüksek basınç kaybı olduğundan, cıvalı manometre kullanılmıştır. Test numunelerini ve diğer filtreleri deney cihazına bağlamak için flanşlardan yararlanılmıştır. Flanşlar borulara vidalanmış olup her iki flanş birbirine clvatalarla monte edilmiştir. Deneye başlamadan önce test numunesi tartılmış ve kaba filtre, HEPA filtre, deney numunesi cihaza monte edilmiştir. Nanofiber tabakalı filtre deney setine bağlanırken havanın nanofiber tarafından girecek olmasına dikkat edilmiştir. Filtrelerin bağlandığı flanşlardan hava sızıntısı olmaması için filtre çevresinde çift tarafı yapışkan hava kanalı contası kullanılmıştır. Deney düzeneğinden 0.5 bar hava geçirilerek sızıntı kontrolü yapılmıştır. Daha sonra tüm vanalar kapatılmıștır. Hava girişindeki küresel ve şiber vana açlarak sisteme 2 bar hava verilmiştir. Kaba partiküllerden ayrılan hava, regülatörün yavaşça açılmasıyla HEPA filtreye girerek, çok küçük partiküllerden ve yağdan arındırılmıştır. Orifise giren temiz havanın fark basıncı 15 mmSS (alın hızı, $0.3 \mathrm{~m} / \mathrm{s}$ ) olacak şekilde manuel olarak basınç regülatöründen ayarlanmıștır. Beş dakika sonunda sistem rejime girdiğinde filtre numunesinde oluşan basınç farkı basınç ölçülerek not edilmiştir. Daha sonra deney seti girişindeki şiber vana kapatılarak ilk deney tamamlanmıştır. Aynı filtreyle ikinci alın hızında ölçüm için şiber vana yavaşça açılmış ve ardından regülatör orifis manometresinde $96 \mathrm{mmSS}$ (0.8 m/s) olacak şekilde ayarlanarak beş dakika sonunda filtre numunesinde oluşan fark basınç not edilmiştir. Benzer işlemler, $247 \mathrm{mmSS}$ (1.3 m/s) orifis fark basıncı olacak şekilde regülatör ayarlanarak 5 dakika sonunda filtre numunesi manometresindeki basınç farkı not edilerek test tamamlanmıştır. Basınç kaybı deneyinden sonra tıkanma kontrolü amacıyla test numuneleri tartılmış ve herhangi bir kütle artışı olmadığı belirlenmiştir.

\subsection{Partikül yakalama deneyleri}

Bir hava filtresinden beklenen, çok sayıda küçük partikülü düşük basınç kaybı oluşturarak yakalamaktır. Zaten filtrelemenin amacı temiz, yani partikülsüz bir hava elde etmektir. Hava filtresinden beklenen bu özelliğin ölçülmesi amacıyla partikül yakalama deneyleri yapılmış ve yakalanan partikül miktarı ile oluşan basınç kaybı ölçülmüştür.

Partikül yakalama miktarının ölçülmesi amacıyla geliștirilen partikül yakalama deney cihazı dört bölümden oluşmaktadır (Şekil 4). Bunlardan ilki, ön filtreleme ve regülatör sistemi olup, basınç kaybı deney setindeki gibi partikül filtreleme ve hava debisini ayarlamak için kullanılmıștır. İkinci bölüm olan akışkan yatak vasıtasıyla, $\mathrm{CaCO}_{3}$ nanopartikülleri uçurulup karışım odasına gönderilmiştir. Karışım odasında homojen bir karışım elde edilmiştir. Üçüncü bölümdeki boșta çalıștırma hattı, deney sisteminin rejime girmesi, deney setinin filtre numunesi söküp takarken sistemin aralıksız çalışması amacıyla tasarlanmıștır. Son bölüm olan filtre numunesi test bölümünde ise, filtreden geçen hava hızının ölçümü yapılarak filtrede oluşan basınç kaybı tespit edilmiştir. Filtrenin tutamadığı partiküller suya gönderilmiştir. Filtreden geçen partiküllerin miktarını ölçmek amacıyla siklon ve sıkıştırılmış elyaf filtre de kullanılmıştır.

Partikül yakalama deneyi süresince akışkan yatak sürekli açık kalmıştır. Akışkan yatak, filtre test numuneleri tartılırken dahi boşta çalıștırma hattına partiküllü hava verilerek çalıştırılmıştır. $\mathrm{Bu}$ nedenle düzgün dağılımlı partikül konsantrasyonu elde edilmiştir.

Akıșkan yatak, belli boyutlardaki katı taneciklerin sıvı gibi davrandıkları duruma verilen isimdir. Yani basınçlı bir gazın, ortamı oluşturan katı tanecikler arasından geçmesiyle oluşur. Bu durumda katılar sıvı 
karakteristiği göstermeye başlar. Ayrıca taneciklerin element yapısı değişmeden, yoğunlukları azalır. Bu olaya yataklama adı verilir.

Akışkan yataktan çıkan partiküllerin iyi karışması için şeffaf hortum içine bir orifis monte edilerek havanın, akışkan yatakla bağlantısı öncesinde hızlandırılması sağlanmıştır. Akışkan yatak olarak iki yarı küre bir plastik kap temin edilerek kaplardan birinin hava giriş kısmında küçük delikler açılmıştır. Bu deliklerin altına H13 sınıfı HEPA filtre konularak partiküllerin deliklerden aşağıya dökülmesi önlenmiștir. Hava giriş borusu, şeffaf hortumla sızdırmaz bir şekilde bağlanmıştır. Partiküllerin çıktığı üst kısım ise üstteki küresel kap delinerek bir pipet yerleştirilmiştir. Bu pipet havanın hızla aktığı orifisin hemen ucuna gelecek şekilde monte edilmiştir. Akışkan yatakla, çok küçük katı parçacıklar hava ile uçurularak nanopartikülü hava elde edilmiştir. Karışım odası için, iki şeffaf huni alınarak alın alına yapıștırılmıștır. Hunilerin her iki ucu da şeffaf bir hortum vasitasıyla monte edilerek sızdırmazlığın sağlanması için yapıştırılmıştır. Partikül yakalama deneylerinde filtre numuneleri belli bir sırayla konmuştur. Nanofiber tabakalı filtrelerin partikül tutma testlerinde, ilk sıraya elyaf filtre, sonra kontrol filtresi, son olarak da nanofiber tabaka kaplı altlık konmuştur (Şekil 5).

Buradaki elyaf filtrenin amacl, kümelenmiș halde gelmesi muhtemel $\mathrm{CaCO}_{3}$ nanopartiküllerden nanofiber tabakayı korumaktır. Nanofiber tabaka ile altlığın oluşturduğu nanofiltre, kontrol filtresiyle yapıştırılmış nanofiber tabaka ortada kalmıştır. Diğer yandan nanofiber tabakanın tıkanmaması için nanopartiküller nano filtreye altlıktan girip nanofiber tabakadan çıkmalıdır. Fakat bu durumda nanofiber tabaka yüksek basınç nedeniyle çok kısa sürede çatlamış ve çatlak büyüyerek filtre delinmiştir. Bu yüzden altlığın nanofiber tabakaya destek olması için nanofiber tabakadan sonra kullanılması gerekmiştir. İşte bu sebepten dolayı nanopartiküller, nanofiber tabakadan önce kontrol filtresine girmesi gerekir ki filtre amacına ulaşsın. H13 sınıfı HEPA filtre numunesi ve mikrofiber filtre numuneleri önüne sadece elyaf filtre konulmuş, kontrol filtresi kullanılmamıştır. Partiküllü hava, ilk önce elyaf filtre, sonra kontrol filtresi, en son nanofiber tabakaya girecek şekilde yerleştirilmiştir (Tablo 6).

Birinci test numunesinin (partikül yakalama deneyinde)sisteme yerleşmiş durumu Şekil 6'de sunulmuştur. Hava giriși tarafına elyaf filtre ardından kontrol filtresi ve son olarak da birinci nanofiltre konmuştur. Bu üç filtre flanşın üzerindeki conta içine yerleştirilerek üzerine ikinci bir conta ve flanş monte edilmiştir.

Partikül yakalama testlerinde nanofiber tabakadan önce hep aynı özellikte kontrol filtresi kullanıldığından nanopartikül filtrelemede altlığın önemi yoktur. Nitekim Leung ve arkadaşları [7] tarafından yapılan çalışmalarda altlığın filtrasyon etkinliğinin \%2'den daha az olduğunu bildirmiştir. Bu nedenle, filtre numunelerinin partikül tutma verimi incelenirken, altlığın filtrasyon etkinliği ihmal edilmiștir. Dolayısıyla mikrofiber filtrelerin kontrol filtresi olarak kullanılması filtrelemeye katkı sağlamıștır. Bu katkı miktarının tespit edilmesi için mikrofiber filtreler de basınç kaybı ve partikül yakalama testine tabi tutulmuştur.

Deneye başlamadan önce, akışkan yatak, karıșım kanalı vanası, boşta çalıştırma hattı ve orifis çıkış vanası açılmış, diğeri kapatılmıştır. Partikül yakalama deney düzeneği girişindeki küresel ve şiber vana hava basıncı 2-2.5 bar olacak şekilde yavaşça açılmıştır. Regülatör yavaşça açılarak, havanın akışkan yatak ve karışım kanalına girmesi sağlanmıştır.

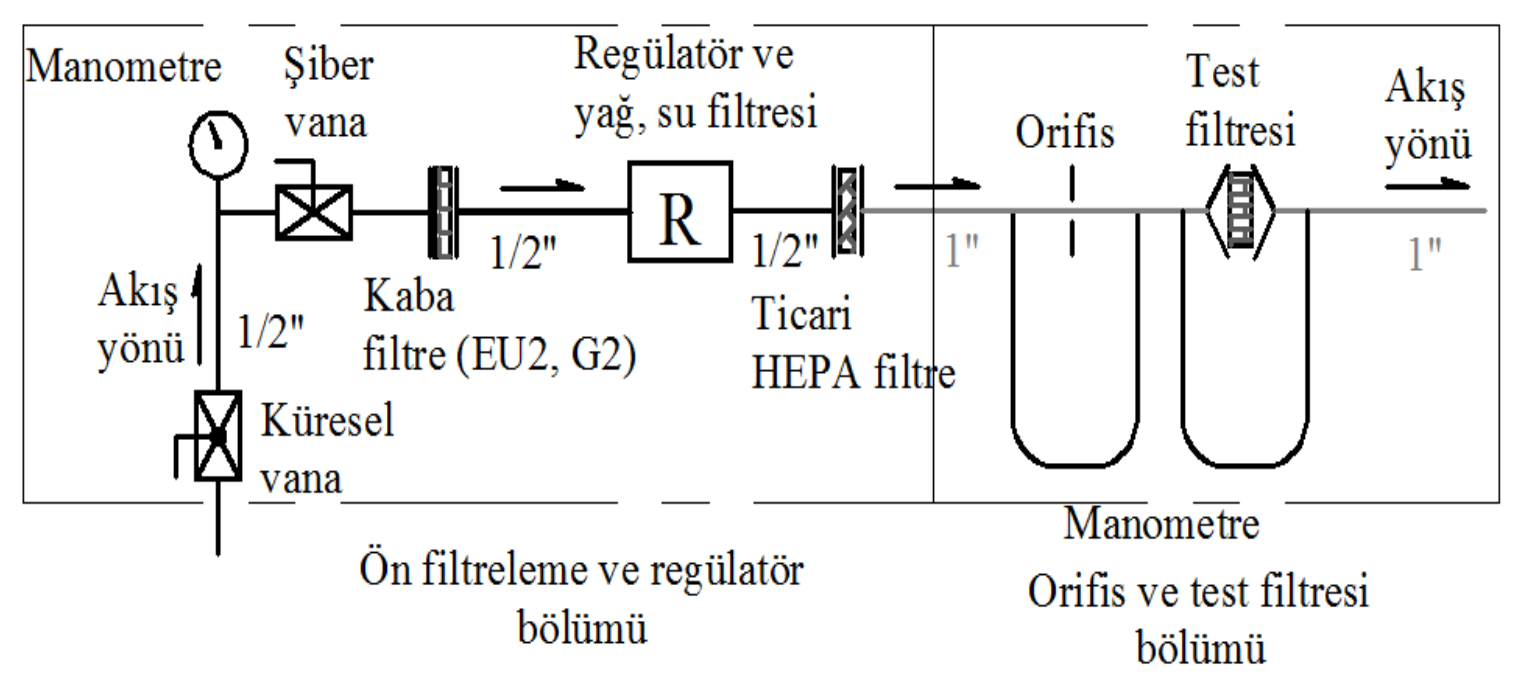

Şekil 3: Basınç kaybı deney setinin şematik görünüşü 


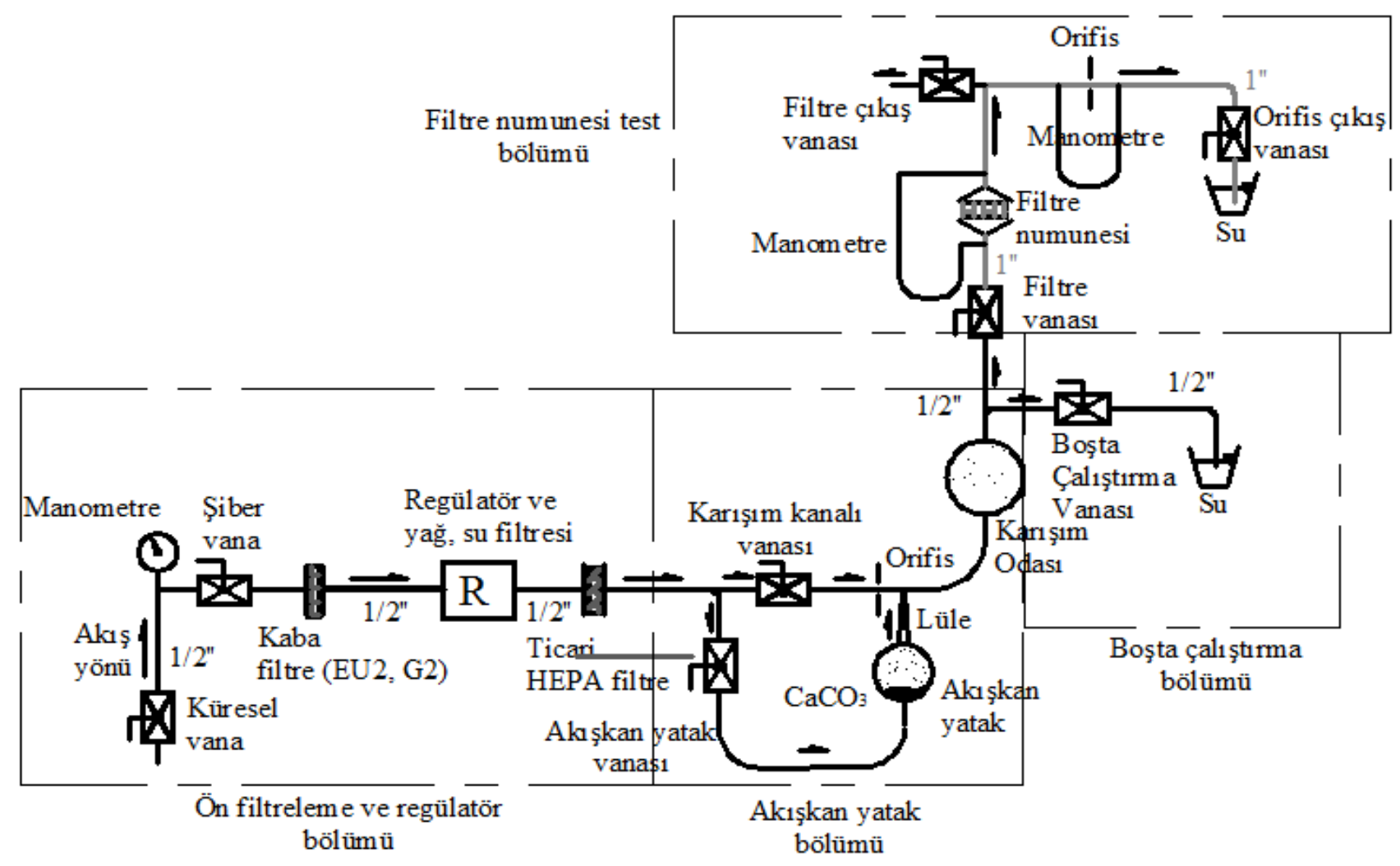

Şekil 4: Partikül yakalama deneysel sisteminin şematik görünüşü

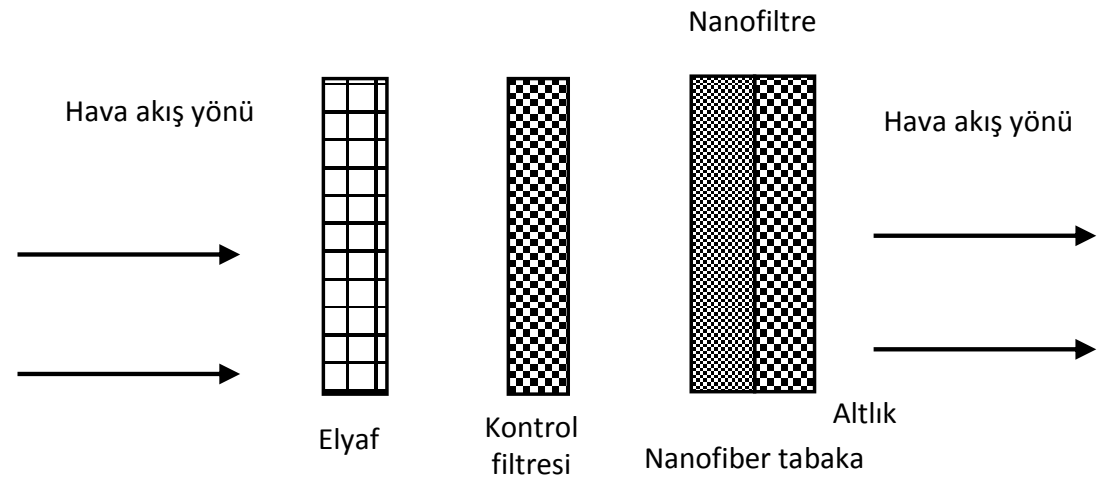

Şekil 5: Partikül testinde filtrelerin yerleşim sırası şematik gösterim

Tablo 6: Partikül yakalama testinde filtre numunesi bölümüne konulan filtrelerin yerleșim sırası

\begin{tabular}{ccccc}
\hline \multirow{2}{*}{ Numune no } & Ön Filtreleme & Kontrol filtresi & Test filtresi & $\begin{array}{c}\text { Nanofiber tabaka ağırlı̆̆ } \\
\left(\mathrm{g} / \mathrm{m}^{2}\right)\end{array}$ \\
\hline 1 & Elyaf filtre & Spunbond & Nanofiber tabaka & 2 \\
2 & Elyaf filtre & Spunbond & Nanofiber tabaka & 2.5 \\
3 & Elyaf filtre & Spunbond & Nanofiber tabaka & 3 \\
4 & Elyaf filtre & Spunbond & Nanofiber tabaka & 3.2 \\
5 & Elyaf filtre & Monofilament & Nanofiber tabaka & 4 \\
6 & Elyaf filtre & - & H13 HEPA filtre & \\
7 & Elyaf filtre & - & Ergitme-Üfleme & \\
8 & Elyaf filtre & - & Spunbond &
\end{tabular}




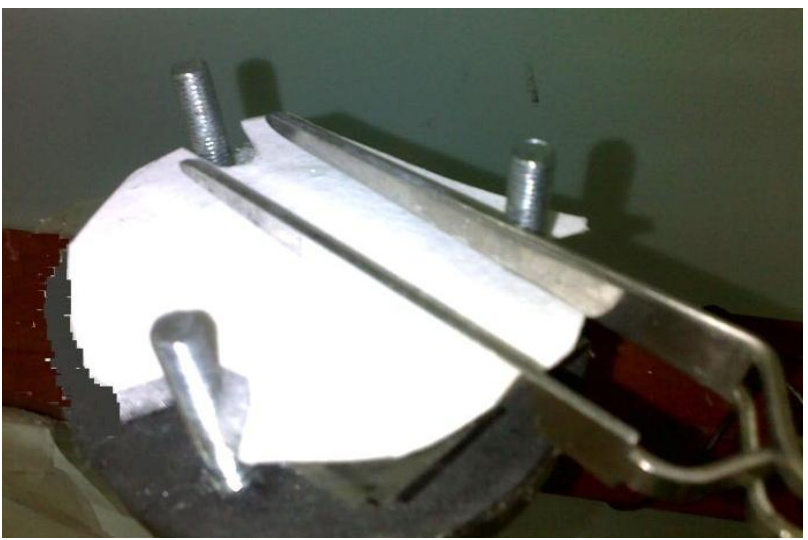

Şekil 6: Birinci nanofiltrenin $\left(2 \mathrm{~g} / \mathrm{m}^{2}\right)$ partikül yakalama deneyine başlamadan önce test cihazına yerleştirilmiş durumu

Karışım kanalında havayla karışan $\mathrm{CaCO}_{3}$, karışım odasina girmiş ve burada homojen $\mathrm{CaCO}_{3}$ nanopartiküllü hava elde edilmiştir. Homojen dağılımlı $\mathrm{CaCO}_{3}$ nanopartiküller, boşta çalıştırma hattından suyun içine doğru ilerlemiştir. Bu şekilde deney sistemi, kararlı rejime geçmesi için 2-3 dak. çalıştırılmıştır. Sistem kararlı hale geçtikten sonra, regülatör yavaşça kısılarak, partikül boşatma vanası kapatılmıştır. Filtre vanası yavaşça açlarak filtre numunesine $\mathrm{CaCO}_{3}$ nanopartikülleri gönderilmiştir. Hava debisi, orifis manometresindeki fark basıncı 15 mmSS olacak şekilde regülatör ayarlanmıştır. Kronometre çalıştırılmış, filtre numunesine bağlı manometreden basınç kaybı okunarak not edilmiştir. Ardından orifis çıkış vanası kapatılmış, filtre çıkış vanası açılmıştır. Beş dakika boyunca nanofiber filtre numuneleri üzerine $\mathrm{CaCO}_{3}$ nanopartiküller gönderilmiş, sonrasında filtre çıkış vanası kapatılarak orifis hattı vanası açılmış test numunesi basınç kaybı not edilmiştir. Partikül boşta çalıştırma vanası açılarak, filtre vanası kapatılmıştır. Sistem çalışmaya devam ederken kontrol filtresi ve filtre numunesi ile filtre çıkışında bulunan sıkıştırılmış elyaf filtreden veya siklondan geçen partikül miktarı hassas terazide birkaç defa tartılmış, ortalama ağırlıklar not edilmiştir. Böylece toplamda yirmibeş dakikalık filtre performans deneyinin ilk beş dakikalık kısmı bitirilmiştir. $\mathrm{Bu}$ şekilde ortalama beş defa filtre numuneleri, partikül tutma testine tabi tutularak, oluşan ilave basınç kaybı ve partikül kazanımları not edilerek performans deneyleri tamamlanmıştır.

\section{Tartışma ve Sonuç}

Nanofiltreler, H13 HEPA filtre, G2 ve G4 sinıfı mikrofiltrelerin aralarındaki farkı görebilmek amacıyla performans testleri yapılmıştır. Performans testleri basınç kaybı ve partikül testlerinden oluşmaktadır. Basınç kaybı testinde, filtreye temiz hava gönderilerek filtrelerde oluşan basınç kaybı ölçülmüştür. Partikül tutma testinde ise, partiküllü hava kullanılarak zamana ve basınca bağlı tutulan partikül miktarı belirlenmiştir. Basınç kaybı testi, 0.3 $\mathrm{m} / \mathrm{s}, 0.8 \mathrm{~m} / \mathrm{s}$ ve $1.3 \mathrm{~m} / \mathrm{s}$; partikül tutma testi $0.3 \mathrm{~m} / \mathrm{s}$ alın hızlarında yapılmıştır. Partikül olarak suyu uçurulmuş $80 \mathrm{~nm}$ ile $120 \mathrm{~nm}$ boyut aralığında küresel formda $\mathrm{CaCO}_{3}$ nanopartiküller kullanılmıştır. $\mathrm{CaCO}_{3}$ nanopartikülleri uçurmak amacıyla akışkan yataktan faydalanılmıştır. Akışkan yatakla $\mathrm{CaCO}_{3}$ nano partikülleri kolayca uçurularak havayla karıştırılmış ve filtre numunelerine gönderilmiștir. Partikül tutma testi, filtrenin tutulan partikül karşısında basınç kaybı değişimini, dolayısıyla filtrenin nasıl davrandığını göstermiştir. Performans deneyleri sonucunda üretilen nanofiltrelerden en yüksek basınç kaybının $1034 \mathrm{mmHgS}$ ile birinci numunede $1.3 \mathrm{~m} / \mathrm{s}$ alın hızında, en düşük basınç kaybının ise $8 \mathrm{mmHgS}$ ile ikinci numunenin $0.3 \mathrm{~m} / \mathrm{s}$ alın hızında meydana geldiği belirlenmiștir. Partikül tutma testinde ise dördüncü numune tıkanmış,üçüncü numune tıkanmaya meyilli olduğu tespit edilmiş, beşinci, altıncs ve ikinci numuneler iyi bir performans sergilemiştir. Nanofiltrelerin yakaladığı partikül miktarı ile basınç kaybı değişimi Şekil 7 de verilmiștir.

Literatürde olduğu gibi, nanofiltrelerde yakalanan partikül miktarı ve basınç kaybı, mikrofiltrelere göre daha yüksektir. Fiberlerin dolayısıyla gözeneklerin küçülmesi nedeniyle hava akışı zorlaştırmıştır. Ayrıca filtrelerde alın hızının artmasıyla, hava fiberlere hızla çarptığından hızı azalmış bu nedenle basınç kaybı yükselmiştir (Tablo 7).

Filtre performans testleri için montajı, işletmesi basit ve ucuz bir deney seti kurulmuştur. Partikül tutma deneylerinde nanopartikül olarak toksin olmayan $\mathrm{CaCO}_{3}$ kullanılmış, bunu uçurmada ise akışkan yataktan faydalanılmıștır. Kurulan bu deney seti farklı filtrelerin basınç kaybını ve partikül yakalama performanslarını karşılaştırmada oldukça başarılı olmuştur.

Filtre performans deneylerinde, nanofiber kesit alanı (nanofiber tabaka kalınlığı) arttıkça, nanopartiküllerin filtreden geçeceği yol uzamış ve kısa bir süre sonra tıkanma gerçekleşmiştir. Tıkanma sonucu basınç çok hızlı bir şekilde artmış, yakalanan partikül miktarı pek değişmemiştir. Bununla birlikte, az miktarda nanofiber kaplanan üçüncü nanofiltre performansının çok fazla arttırmadığı görülmüştür. Bu yüzden, nanofiber kaplama ağırlığının gereğinden az veya fazla olmaması gerekir. Az kaplanan nanofiber tabakanın filtre performansına katkı sağlamadığı, çok kaplanan nanofiber tabakanın ise, tıkanarak ömrünü kısa sürede doldurduğu, optimum filtrelemenin, orta dereceli nanofiber çapında (200 $\mathrm{nm}$ ) ve kaplama ağırlığında (2.5 g) olduğu tespit edilmiştir.

Genel olarak küçük çaptaki nanofiberlerden oluşan nanofiltreler ince tabaka halinde, büyük çapa sahip nanofiberlerin oluşturduğu nanofiltreler kalın tabaka halinde kaplanarak kullanılması filtreleme performansını yükseltmiştir. Nitekim büyük çapa 
sahip H13 sınıfı HEPA filtrenin kalın olması ve 200 nm çapa sahip ikinci numunenin orta kalın olması durumlarında filtreleme performanslarının yükselttiği görülmüştür.

Nanofiber içindeki boncuklu yapı, filtreleme kalitesini genellikle olumlu yönde etkilemiştir. Etkin filtrasyon için, nanofiber tabakasının büyük (5-8 $\mu \mathrm{m})$ ve düzgün dağılımlı boncuklu yapıya sahip olması gerekir. Nitekim bu durum ikincinin partikül tutma testinde görülmüştür. Fakat nanofiltrenin büyük boncuklu olması yüksek performans için yeterli değildir. Bunun yanında nanofiberlerin optimum kalınlıkta kaplanmış olması gerekir.

Spunbond altlıklar, nanofiltre olarak en iyi performansı sağlamıştır. $\mathrm{Bu}$, spunbond altlığın rijit, mukavim ve yüzeyinin pürüzlü olmasından kaynaklanmıştır. Bu nedenle herhangi bir katlama yapılmaksızın düz bir konstrüksiyonda iken 1 atm'den daha yüksek basınçlara dayanmış ve nanofiltre tabakayı bırakmamıștır. Spunbond mikro filtre nanofiltre ile iyi uyum sağlamış ve kolay kolay birbirinden ayrılmamıştır.

Birinci nanofiber tabakanın az miktarda kaplanmasıyla ince bir tabaka elde edilmiş bu nedenle fazla nanopartikül yakalanamamıştır. Nanofiber kaplama ağırlığının artmasıyla kritik bir değere kadar yakalanan nanopartikül miktarı artmış, daha sonra hızlı bir şekilde azalmıştır. Bunun nedeni nanofiber tabaka ağırlığının artmasıyla nanofiber tabaka kalınlaşmış ve filtre geçirgenliği azaldığı için yakalanan nanopartikül miktarı azalmıștır.

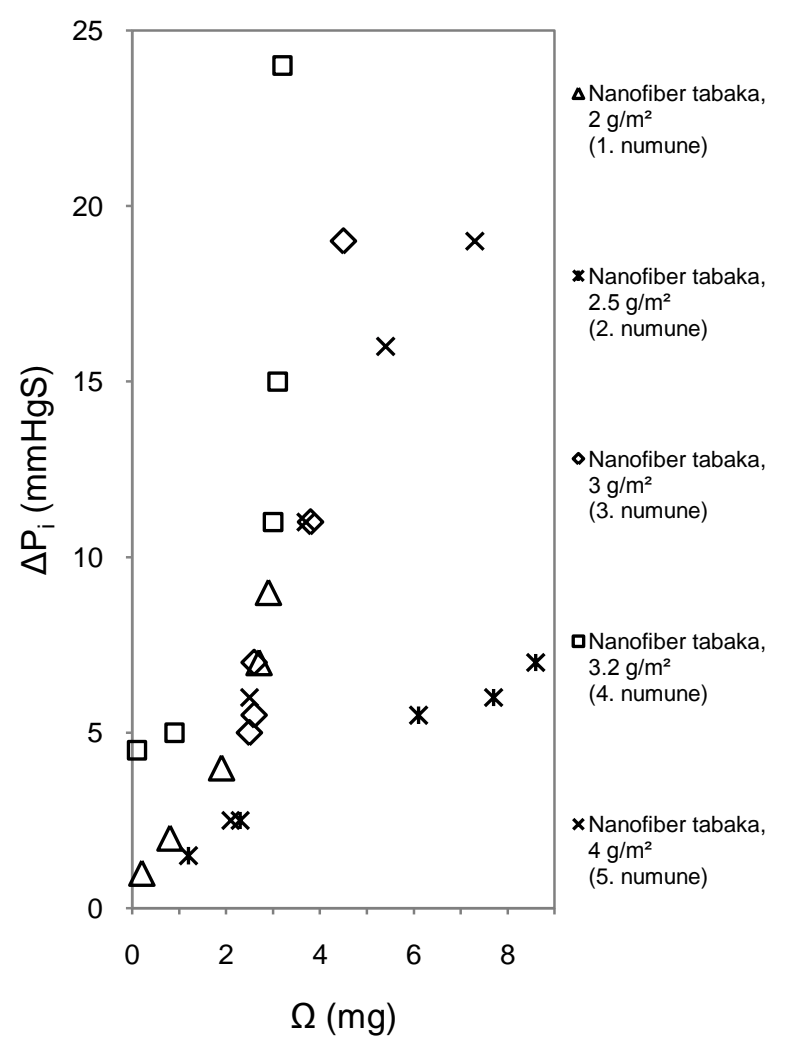

Şekil 7: Nanofiltrelerin yakaladığı partikül miktarıile basınç kaybı değişimi

Tablo 7: Partikül yakalama testinde filtre numunesi basınç kaybı değișimi

\begin{tabular}{|c|c|c|c|c|c|c|}
\hline Num.no & Ağırlık $\left(\mathrm{g} / \mathrm{m}^{2}\right)$ & $\emptyset_{\text {ort. }}(\mathrm{nm})$ & $\Delta \mathrm{P}_{\text {ort. }}(\mathrm{mmHgS})$ & $\Delta \mathrm{P}_{\mathrm{i}}(\mathrm{mmHgS})$ & $\Omega(\mathrm{mg})$ & $\mathrm{t}_{\mathrm{p}}$ (dak.) \\
\hline 1 & 2 & 200 & 1.5 & $\begin{array}{l}1 \\
2 \\
4 \\
7 \\
9 \\
\end{array}$ & $\begin{array}{l}0.2 \\
0.8 \\
1.9 \\
2.7 \\
2.9 \\
\end{array}$ & $\begin{array}{l}5 \\
10 \\
15 \\
20 \\
25 \\
\end{array}$ \\
\hline 2 & 2.5 & 193 & 7.5 & $\begin{array}{l}1.5 \\
2.5 \\
5.5 \\
6 \\
7 \\
\end{array}$ & $\begin{array}{l}1.2 \\
2.3 \\
6.1 \\
7.7 \\
8.6 \\
\end{array}$ & $\begin{array}{l}5 \\
10 \\
15 \\
20 \\
25 \\
\end{array}$ \\
\hline 3 & 3 & 98 & 200 & $\begin{array}{l}5 \\
5.5 \\
7 \\
11 \\
19 \\
\end{array}$ & $\begin{array}{l}2.5 \\
2.6 \\
2.6 \\
3.8 \\
4.5 \\
\end{array}$ & $\begin{array}{l}5 \\
10 \\
15 \\
20 \\
25 \\
\end{array}$ \\
\hline 4 & 3.2 & 77 & 77.5 & $\begin{array}{l}4.5 \\
5 \\
11 \\
15 \\
24 \\
\end{array}$ & $\begin{array}{l}0.1 \\
0.9 \\
3 \\
3.1 \\
3.2 \\
\end{array}$ & $\begin{array}{l}5 \\
10 \\
15 \\
20 \\
25 \\
\end{array}$ \\
\hline 5 & 4 & 137 & 20 & $\begin{array}{l}2.5 \\
6 \\
11 \\
16 \\
19\end{array}$ & $\begin{array}{l}2.1 \\
2.5 \\
3.7 \\
5.4 \\
7.3\end{array}$ & $\begin{array}{l}5 \\
10 \\
15 \\
20 \\
25\end{array}$ \\
\hline
\end{tabular}


Filtrenin şişmesi, performans arttırıcı bir rol oynamıştır. Filtrelerin şişmesiyle, gözenekler açılmış, basınç kaybı biraz düşerken, yakalanan partikül miktarı artmıştır. Filtrenin şişmesi ile oluşabilecek mikro çatlaklardan korunmak için nanofiberlerin yeterince mukavim ve sünek olmalıdır. Bunun için nanofiber kaplama kalınlı̆̆ının orta seviyede olması gerekir. Aksi halde nanofiberler yırtılarak ömrünü kısa bir sürede tamamlar.

Nanofiber tabaka tarafindan tutulamayan, nanofiltreden geçen $\mathrm{CaCO}_{3}$ nanopartiküllerinin miktarı su, sıvı yağ, siklon ve sıkıştırılmış keçe kullanılarak belirlenememiştir. Filtreden geçen partikül boyutunun tespit edilememesi, filtreden geçen partikül boyutunun dolayısıyla miktarının çok az olmasıdır.

Nanofiber tabaka altlıklara kaplandıktan sonra altlık arkada kalacak şekilde konulmalıdır. Nanofiltre önüne kalın kesitli ve küçük çaplı (mikro seviyede) kontrol filtresi konması, filtrenin filtreleme performansını arttırıcı bir rol oynamıștır. Bunun nedeni, kalın ve küçük çaplı bir mikro filtreden çıkan nanopartikül yavaşlayarak ve bir kısmı tutularak nanofiltreye girmesidir.

Partikül tutma testinden sonra filtre numunelerini düzleștirecek, partikülleri dökülecek şekilde konulmamasına özen gösterilmelidir. Bunun için her bir numune yeterli büyüklükte bir kaba ayrı ayrı konmalıdır.

Deney cihazında kullanılan vanalar yavaşça açılıp kapatılmalıdır. Aksi halde, manometrelerin içindeki akışkanlar havayla dışarı kaçabilir, filtreler patlayabilir, ani basınç artışından sızdırmazlık azalabilir.

Filtrelerin takıldığı flanşlarda cıvata-somun bağlantısı kullanılmıştır. Deney esnasında cıvataları söküp takmak zahmetli ve zaman alıcı bir yöntem olduğundan, flanşların yeterince büyük olması, cıvataların flanşlara kaynak edilmesi ve kelebek somun kullanılması tavsiye edilebilir.

\section{Teşekkür}

Bu çalışma Selçuk Üniversitesi BAP Koordinatörlüğü Proje No: 11401130 tarafından desteklenmiştir.

\section{Kaynaklar}

[1] Duran K, Öneş AM. "Nonwovenların Filtrasyonda Kullanımı". TekstilveKonfeksiyonDergisi, V.5, 337342, 1993.

[2] Vaughn E, Ramachandran G. "Fiberglass Synthetic Air Filtration Media". International Nonwovens Journal, 11: 3, 41-51, 2002.

[3] Frank KK. "From Textile to Geotextiles". Seminar in Honour of Prof. Robert Koerner, Drexel University, Philadelphia, USA, 2004.

[4] Hardman E. Handbook of Technical Textiles. Edited by Horrocks AR. Anand SC, Woodhead Publishing, Textiles in Filtration, 317-357, 2000.

[5] Hutte, IM. Handbook of Nonwoven Filter Media. Elsevier Science \& Technology Books, USA, 2007

[6] Sutherland, K., Purchas, D.B., Handbook of Filter Media. 2nd. Edition, Elsevier, 2002.

[7] Leun, WWF, Hung CH, Yuen PT. "Effect of face velocity, nanofiber packing density and thickness on filtration performance of filters with nanofibers coated on a substrate". Seperation and Purification Tecnology, (71) 30-37, 2010.

[8] Dincer, K, Önal, G, Akdemir, A. Selbes, M. "Elektro-eğirme yöntemiyle nanofiber tabakalı hava filtresi üretimi ve karakterizasyonu". SUJEST, 4: 4, 2147-9364, 2016. 